\title{
TIPPING POINTS IN THE EARTH SYSTEM
}

\section{KEY MESSAGES}

- Tipping Points are critical thresholds beyond which a system reorganises, often abruptly and/or irreversibly.

- There are several climate tipping elements of concern: large-scale components of the Earth System that may pass a tipping point, such as ice sheets and rainforests.

- Positive feedback loops, or self-reinforcing feedbacks, are key drivers of tipping points, and could lead to long-term irreversible changes.

- Passing certain climate tipping points could have severe local impacts, such as extreme temperatures, droughts, forest fires, ice sheet loss and sea level rise.

- There is a risk of interactions between different tipping elements, which could result in the triggering of a global cascade of tipping points.

\section{INTRODUCTION}

Many of the impacts of climate change manifest themselves as continuous, incremental changes.

There is a near-linear relationship between cumulative $\mathrm{CO}_{2}$ emissions and the increase in global surface temperatures': as the levels of $\mathrm{CO}_{2}$ in the atmosphere increase, so does global warming, causing a range of incremental changes such as rising ocean heat content, sea level rise and declining Arctic Sea ice cover - each creeping up little by little.

However, there is mounting evidence that some parts of the Earth system may also be at risk of abrupt and potentially irreversible changes, driven by the cumulative impact of incremental global warming. Such a non-linear transition could be triggered if a critical threshold in global temperature - a "tipping point" - is crossed, when a small change could push a system into a completely new state, with potentially catastrophic impacts.
There are multiple potential "tipping elements" of concern: large scale components of the Earth system that could pass a tipping point. These can be broadly classified in three groups:

- Melting ice masses, e.g., disintegration of the ice sheets in Greenland or West Antarctica

- Circulation pattern changes, e.g., shutdown of Atlantic Meridional Overturning Circulation

- Biome shifts, e.g., dieback of the Amazon Rainforest, or coral reef die-off

There are significant uncertainties associated with the processes of tipping points, in terms of their likelihood of occurring as well as the timescales on which they might take place. While we think of tipping points as "abrupt" transitions, these processes can unfold over centuries to millennia (e.g., in the case of ice sheets disintegrating), over decades to centuries (e.g., changes to ocean circulations), or years to decades (especially in cases where human interference is an additional driver, e.g., deforestation of the Amazon rainforest). ${ }^{2}$

\section{Author:}

| Dr Erik Mackie, Engagement Manager, Cambridge Zero, University of Cambridge. ejm222@cam.ac.uk

\section{Acknowledgments:}

This briefing draws upon two panel discussions on tipping points organised by the COP26 Universities Network, each with 4 expert panellists. The first, on Tipping Points and Abrupt Climate Responses, took place during the COP26 Universities Climate Risk Summit on 29th September 2021, with panellists Prof Rachel Warren, Prof Niklas Boers, Dr Sebastian Rosier and Dr Levke Caesar. The second, on Climate Risk and Tipping Points in the Polar Regions, took place in the Arctic Basecamp at the UNFCCC COP26 Climate Summit in Glasgow, on 8th November 2021, with panellists Dr Tamsin Edwards, Prof Michael Bravo, Dr Louise Sime and Gabrielle Kleber. We thank all panellists for their contributions. 
In this technical briefing, we will first define tipping points and tipping elements, then explore several tipping elements in more detail and discuss the questions of abruptness, irreversibility, timescales and uncertainties for each of them. We also investigate the possibility of developing early warning systems for tipping points, and the risk of cascades of interacting tipping points, where one tipping point could trigger another.

\section{DEFINING TIPPING POINTS}

Here we define tipping points and other associated key terms and concepts. These definitions are also summarised in Table 1.

\section{I. TIPPING POINTS \& TIPPING ELEMENTS}

The Intergovernmental Panel on Climate Change (IPCC) defines tipping points as "critical thresholds beyond which a system reorganises, often abruptly and/or irreversibly".1,3 Scientific understanding of abrupt climate change and irreversibility has advanced considerably in recent years, and there is evidence that such abrupt changes have occurred in the Earth's geological history, e.g. during deglaciations after past ice ages. ${ }^{4}$ The recent 6th Assessment Report (AR6) of Working Group I of the IPCC states that there is no evidence in climate projections of such a non-linear response occurring on a global scale during this century. However, the report also states with high confidence that "abrupt responses and tipping points of the climate system, such as strongly increased Antarctic ice sheet melt and forest dieback, cannot be ruled out."11

"Tipping elements" are defined as large-scale components of the Earth System that may pass a tipping point. ${ }^{3}$ There are multiple potential tipping elements that could be triggered by increased global warming, including: shutdown of the Atlantic Meridional Overturning Circulation (AMOC), disintegration of the ice sheets in West Antarctica \& Greenland, Amazon rainforest dieback, West African \& Indian monsoon shifts, permafrost loss, coral reef die-off and Boreal forest shifts. We will discuss some of these in more detail below.

If such an abrupt climate tipping point were to occur, this could have severe local impacts, such as extreme temperatures, droughts, forest fires and ice sheet loss, and could potentially result in long-term irreversible changes. Tipping points are therefore often referred to as "High-risk, low-probability" events: the probability of such an event occurring is deemed to be low, but the risks associated with a tipping point being crossed are very high, with potentially catastrophic and far-reaching consequences. ${ }^{5}$

\subsection{POSITIVE FEEDBACKS}

The climate system also contains positive feedback loops, or self-reinforcing feedbacks. These are processes in a system where a change in a given direction causes additional change in the same direction i.e., the effects of a small perturbation on a system include an increase in the magnitude of the original perturbation. A well-known example from the climate system is the ice-albedo effect: global warming is reducing Arctic sea ice cover during summer months, resulting in more of the darker sea surface being exposed. Water has a lower albedo than ice (it reflects less sunlight), so it absorbs more heat, resulting in a warmer ocean and further melting of sea ice, and so on. Another example is permafrost melt in the Arctic: as temperatures rise, Arctic permafrost melts and releases methane, a potent greenhouse gas $(\mathrm{GHG})$, which in turn causes further global warming.

Positive feedback loops such as these are key drivers of tipping points, as they can quickly amplify small changes which could push a system to cross a critical threshold. Positive feedback loops are also often associated with irreversibility, but their effects are not necessarily irreversible. For example, modelling evidence shows that Arctic sea ice cover is reversible against global mean temperature ${ }^{6}$, i.e. if $\mathrm{GHG}$ emissions were reduced and global temperatures were to fall, then the Arctic sea ice could stabilise and recover.

\subsection{IRREVERSIBILITY \& HYSTERESIS}

Whether or not a tipping point is irreversible is highly dependent on the characteristics of each individual system. In some cases, evidence shows that once the system has made an abrupt shift to a different state i.e., crossed a tipping point, then it will not easily return to its original state, even if the climate forcing is removed. The system could then remain in its new, altered state for a considerable amount of time, or even permanently. Such a system is described as undergoing a "bifurcation point": the system has two stable states and once it has switched from one stable state to another it is subsequently very difficult or even impossible to return to the previous state.?

This behaviour is known as "hysteresis", a mathematical term describing the dependency of the state of a system on its history. A tipping point with hysteresis behaviour is considered irreversible, at least on human-relevant timescales. For example, the Greenland Ice Sheet (GrIS) and parts of the West Antarctic lce Sheet (WAIS) are believed to exhibit hysteresis behaviour ${ }^{8,9}$ : if these ice sheets were to cross a critical temperature threshold that led to their partial or complete disintegration (over centuries to millennia), then simply lowering global temperatures would not be enough to reverse this change and loss 
of the ice sheet becomes irreversible, leading to much higher levels of sea level rise. It would likely require another ice age to "re-grow" the ice sheet.

It is important to emphasise that not all tipping points are irreversible. A tipping point can also exhibit an abrupt and highly non-linear change without hysteresis behaviour, meaning that the change could be reversed if the climate forcing is removed. Arctic sea ice cover, as described above, is an example of a tipping point without hysteresis behaviour. Whether or not tipping points are irreversible remains a topic of ongoing research and is one of the many uncertainties associated with tipping points.

\section{Table 1: Definitions of tipping points and} associated terms

\begin{tabular}{l|l} 
Term & Definition \\
\hline Risk & $\begin{array}{l}\text { The potential for adverse consequences } \\
\text { for human or ecological systems, } \\
\text { recognising the diversity of values } \\
\text { associated with such systems. In the } \\
\text { context of climate change, risks can } \\
\text { arise from potential impacts of climate } \\
\text { change as well as human responses to } \\
\text { climate change. }\end{array}$ \\
\hline Tipping & $\begin{array}{l}\text { Critical thresholds beyond which a } \\
\text { system reorganises, often abruptly } \\
\text { and/or irreversibly. }\end{array}$ \\
\hline Tipping & $\begin{array}{l}\text { A large-scale component of the Earth } \\
\text { Eystem that may pass a tipping point. }\end{array}$ \\
\hline Plement & $\begin{array}{l}\text { Process where the effects of a small } \\
\text { perturbation on a system include } \\
\text { an increase in the magnitude of the } \\
\text { original perturbation. }\end{array}$ \\
\hline Hysteresis & $\begin{array}{l}\text { The dependency of the state of } \\
\text { a system on its history, referring } \\
\text { here to a system with bi-stability } \\
\text { passing a bifurcation point leading } \\
\text { to irreversible change. }\end{array}$ \\
\hline
\end{tabular}

\subsection{EARLY WARNING SIGNALS}

Research suggests that it is possible, in principle, to develop early warning signals for tipping points by using observational data and time series to detect when a certain tipping element is approaching a critical transition ${ }^{10}$. When a system approaches a critical transition or bifurcation point, it displays a critical slowing down in the observations, which is characterised by increases in the variance and autocorrelation of the observed signal, two mathematical quantities that describe the statistical behaviour of the signal. ${ }^{11}$ If these increases in the variance and autocorrelation can be detected in observations, they could be used as indicator that the observed system is approaching a critical transition, or at least that it has lost stability, thus providing an early warning signal of an approaching tipping point. This theoretical approach has recently been applied in practice to provide early warning signals that the AMOC and the Greenland Ice Sheet may already be approaching tipping points..$^{12,13}$

\section{TIPPING ELEMENTS IN THE EARTH SYSTEM}

In this section we discuss several notable tipping elements in the Earth system in further detail: the AMOC, the West Antarctic and Greenland lce Sheets, and the Amazon rainforest. We explore some of the processes and uncertainties associated with each of them. A geographical illustration of these and other potential tipping elements and their impacts is also shown in the diagram in Figure $1 .{ }^{14}$

\section{I. ATLANTIC MERIDIONAL OVERTURNING CIRCULATION [AMOC]}

The AMOC is an important system of ocean currents that distributes warm water around the Atlantic. The AMOC brings warm water from the tropics to Europe and forms a crucial part of the global ocean circulation system that transports heat around the World. A shutdown or collapse of the AMOC would have catastrophic consequences around the world, including impacts on the climate of Western Europe. A scenario where the $\mathrm{AMOC}$ crosses a tipping point and shuts down was famously portrayed in the 2004 Hollywood blockbuster "The Day After Tomorrow", albeit with many scientific inaccuracies. This does however represent a real physical mechanism, and it has been shown that an influx of meltwater from the Greenland Ice Sheet into the North Atlantic Ocean can contribute to a weakening of the AMOC. ${ }^{15}$ There is increasing evidence from observations as well as paleoclimate proxies that the AMOC has weakened significantly during past decades ${ }^{16,17}$, and that it is currently at its weakest state in at least a millennium. ${ }^{18}$ The observational record shows that after a long stable period, this weakening started in the 19th century and was followed by a second more rapid decline in the mid-20th century. This recent decline could be an indication of a critical slowing down of the AMOC, which may be an early warning signal that it is losing stability and may be approaching a tipping point..$^{12}$

\subsection{WEST ANTARCTIC ICE SHEET [WAIS]}

Projections of future sea level rise largely follow a linear relationship with warming: the more temperatures increase, the more sea levels rise, as the ocean water heats up and expands, and glaciers and ice sheets melt. The main source of uncertainty in these projections is mass loss from the West Antarctic lce Sheet, which holds enough ice to raise global sea levels by approximately $3 \mathrm{~m}$ if it were to be lost completely. There are concerns that parts of the WAIS could collapse abruptly, through a process called "marine ice sheet instability" (MISI): once a critical threshold 
is crossed this could trigger a self-sustaining retreat of certain glaciers on the WAIS, committing them to rapid and irreversible ice loss and leading to substantial increases in global sea level rise. Recent modelling of Pine Island Glacier, one of the fastest changing outlet glaciers in West Antarctica, has identified three distinct tipping points in response to increases in oceaninduced melting, which could lead to a retreat of the entire glacier and initiate a collapse of the WAIS. ${ }^{19}$

Another process called "marine ice-cliff instability" $(\mathrm{MICl})$ could trigger a further runaway acceleration in the retreat of the WAIS, and may result in a nonlinear response of sea levels rising by more than $1 \mathrm{~m}$ by $2100^{20}$, with disastrous impacts on coastlines globally. The $\mathrm{MICl}$ process is disputed amongst climate scientists however ${ }^{21}$, and there is no observational evidence of it yet, leading the IPCC to include this as a "low-likelihood, high-impact" scenario in the AR6 sea level projections. ' However, recent observational evidence from Antarctica shows that the amount of damage to ice shelves, from meltwater-driven fracturing or crevassing, can affect the rate at which the ice sheet responds to warming and could accelerate its retreat ${ }^{22,23}$, which may lead to hysteresis behaviour of the WAIS.

\subsection{GREENLAND ICE SHEET [GRIS]}

The Greenland Ice Sheet could raise global sea levels by approximately $7 \mathrm{~m}$, if it were to be lost completely. Melting of the GrlS is accelerating, and the IPCC AR6 states that continued ice loss is virtually certain and it has high confidence that total ice loss will increase with cumulative GHG emissions. 'The GrIS is particularly vulnerable since the Arctic is warming 2.5 times faster than the global average. A tipping point for complete disintegration of the GrIS is unlikely to be abrupt, but there is likely to be a critical temperature threshold beyond which its eventual collapse (over millennia) becomes irreversible, with modelling estimates placing this threshold at around $1.6^{\circ} \mathrm{C}$ above pre-industrial levels. ${ }^{8}$ The key tipping point driver for the GrlS is the positive "meltelevation" feedback: as the ice sheet melts, more ice is exposed to warmer temperatures at lower elevations, thus driving further melting, and so on. Recent observational evidence of a critical slowing down may be an early warning signal that the GrlS is approaching a tipping point $t^{13}$.

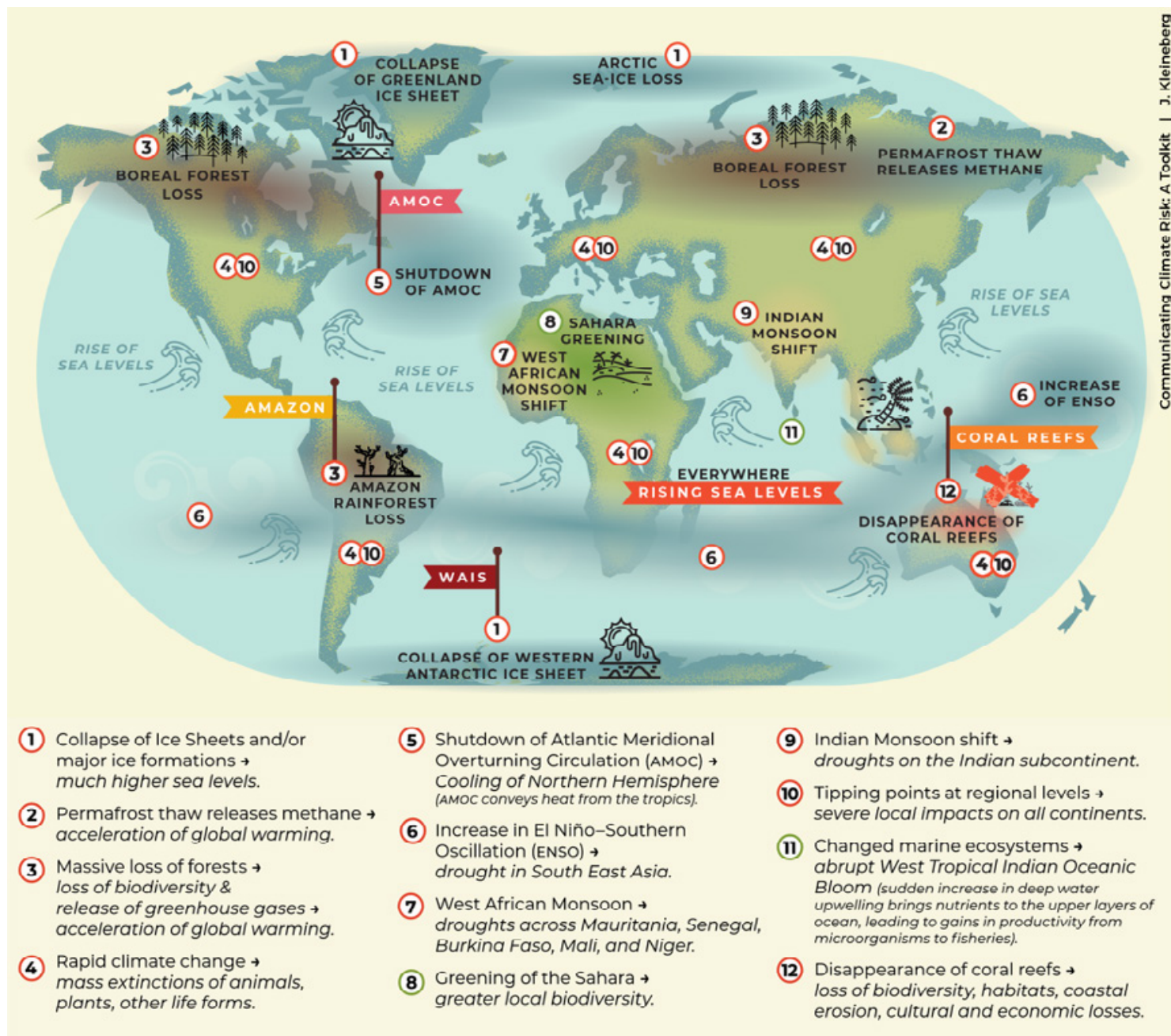

Figure 1: Illustrative diagram depicting some potential tipping elements in the Earth system and their impacts. Image from: Walton et al, 2021, Communicating Climate Risk: A Toolkit. ${ }^{14}$ 
Both for the WAIS and the GrIS, the probability of complete loss of either ice sheet over millennia increases with higher temperatures. The longer we sustain warming above pre-industrial levels, the greater ice loss will be and the greater the impact on global sea level rise. By 2100, we are likely to see between $0.5-1 \mathrm{~m}$ of sea level rise globally, depending on the level of warming. By 2300, sea levels could rise by between $0.5-3 \mathrm{~m}$ if warming is limited to $1.5-2^{\circ} \mathrm{C}$, but increases of up to $7 \mathrm{~m}$ or more cannot be ruled out with high emissions.

\subsection{AMAZON RAINFOREST}

The Amazon rainforest is the largest in the world and is strongly dependent on very wet conditions to remain sustainable. The rainforest generates about half of its own rainfall through evapotranspiration ${ }^{24}$ : recycling water from the soil and plants back into the atmosphere, and helping to drive convection which creates more rainfall. This means that if either the amount of rainfall or the amount of forest is reduced, this could result in a shift to a drier climatic state which can no longer sustain a rainforest. If this happens, the rainforest could pass a tipping point and eventually turn into an ecosystem resembling a savannah. ${ }^{25}$ Climate change induced warming, droughts, wildfires and human deforestation are all drivers of this process. Recent evidence suggests that up to $17 \%$ of the Amazon basin is now affected by forest degradation ${ }^{26,27}$, more than previously thought, and that up to $18 \%$ of the area has already been deforested. ${ }^{28}$ Interactions between climatic changes and direct human-induced changes such as deforestation could lead to regime shifts and potential tipping points in some parts of the Amazon. ${ }^{29}$ However, there remains much uncertainty about the timescales and critical thresholds associated with these processes. ${ }^{25}$

\section{RISK OF INTERACTING AND CASCADING TIPPING ELEMENTS}

There is increasing concern about interactions between different tipping elements, and that the impacts of one tipping point could contribute to the triggering of another tipping point, and so $\mathrm{on}^{5}$. Such interactions could occur through ocean or atmospheric circulation, or through positive feedbacks that increase global temperatures or GHG levels. An example of such interaction between tipping elements is illustrated in Figure 2: research shows that retreat of the WAIS can be directly influenced by sea-level rise as a result of increased meltwater from the $\mathrm{GrIS}^{30}$. In addition, the increased meltwater influx from the GrlS in the North Atlantic can contribute to the weakening of the $\mathrm{AMOC}^{15}$. In turn, AMOC slowdown could alter precipitation patterns over the Amazon, which may either enhance or reduce rainfall in this region ${ }^{31}$. Interactions between tipping elements could have either stabilising or destabilising effects, and there remains much uncertainty about these processes.

There is an additional risk that these interactions between individual tipping elements could result in the triggering of a global cascade of tipping points, which some have argued could tip the Earth System into a permanent, less habitable climatic state, or "Hothouse Earth". 32,5 Recent modelling studies suggest that the interactions between the four tipping elements shown in Figure 2 could lower their individual critical temperature thresholds, and that this risk of tipping cascades increases strongly between 1 and $3{ }^{\circ} \mathrm{C}$ of global warming above pre-industrial levels. ${ }^{33}$ Ultimately, this could result in a "domino effect" of tipping elements being triggered globally, with catastrophic impacts and additional risks of triggering societal risk cascades (see our additional Climate Risk Note "The Cascading Climate Crisis" by Luke Kemp, for more details on risk cascades).

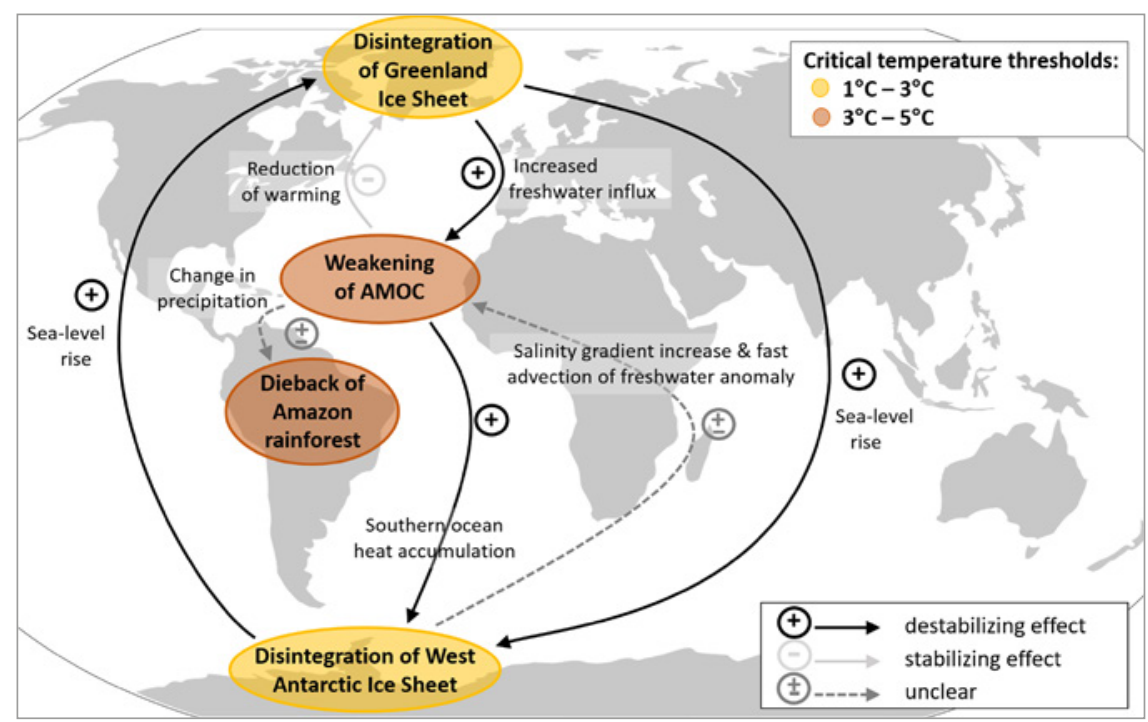

Figure 2: Diagram illustrating physical interactions between 4 key tipping elements that are already under stress today from global warming. Image from Martin et al $(2021)^{2}$, adapted from Wunderling et al $(2021)^{33}$. 


\section{CONCLUSION}

While there remain many uncertainties about the critical temperature thresholds and processes involved in particular tipping elements, it is clear that the risks associated with triggering Earth System tipping points are significant and could lead to catastrophic impacts around the world. As such, the priority of society and policy should be to avoid the passing of tipping points at all costs. By reducing $\mathrm{GHG}$ emissions in line with the Paris Agreement goals and limiting global warming to $1.5^{\circ} \mathrm{C}$ above pre-industrial levels, the risk of crossing critical thresholds in the climate system can be significantly reduced. Climate tipping points really are "too risky to bet against"

\section{REFERENCES}

1. IPCC. Summary for Policymakers. In Climate Change 2021: The Physical Science Basis. Contribution of Working Group I to the Sixth Assessment Report of the Intergovernmental Panel on Climate Change; MassonDelmotte, V., Zhai, P., Pirani, A., Connors, S. L., Péan, C., Berger, S., Caud, N., Chen, Y., Goldfarb, L., Gomis, M. I., Huang, M., Leitzell, K., Lonnoy, E., Matthews, J. B. R., Maycock, T. K., Waterfield, T., Yelekçi, O., Yu, R., Zhou, B., Eds.; Cambridge University Press, 2021.

2. Martin, M. A.; Sendra, O. A.; Bastos, A.; Bauer, N.; Bertram, C.; Blenckner, T.; Bowen, K.; Brando, P. M.; Rudolph, T. B.; Büchs, M.; Bustamante, M.; Chen, D.; Cleugh, H.; Dasgupta, P.; Denton, F.; Donges, J. F.; Donkor, F. K.; Duan, H.; Duarte, C. M.; Ebi, K. L.; Edwards, C. M.; Engel, A.; Fisher, E.; Fuss, S.; Gaertner, J.; Gettelman, A.; Girardin, C. A. J.; Golledge, N. R.; Green, J. F.; Grose, M. R.; Hashizume, M.; Hebden, S.; Hepach, H.; Hirota, M.; Hsu, H.-H.; Kojima, S.; Lele, S.; Lorek, S.; Lotze, H. K.; Matthews, H. D.; McCauley, D.; Mebratu, D.; Mengis, N.; Nolan, R. H.; Pihl, E.; Rahmstorf, S.; Redman, A.; Reid, C. E.; Rockström, J.; Rogelj, J.; Saunois, M.; Sayer, L.; Schlosser, P.; Sioen, G. B.; Spangenberg, J. H.; Stammer, D.; Sterner, T. N. S.; Stevens, N.; Thonicke, K.; Tian, H.; Winkelmann, R.; Woodcock, J. Ten New Insights in Climate Science 2021: A Horizon Scan. Global Sustainability 2021, 4, e25. https://doi.org/10.1017/sus.2021.25.

3. Lenton, T. M.; Held, H.; Kriegler, E.; Hall, J. W.; Lucht, W.; Rahmstorf, S.; Schellnhuber, H. J. Tipping Elements in the Earth's Climate System. Proc Natl Acad Sci USA $2008,105(6), 1786$. https://doi.org/10.1073/pnas.0705414105.

4. Brovkin, V.; Brook, E.; Williams, J. W.; Bathiany, S.; Lenton, T. M.; Barton, M.; DeConto, R. M.; Donges, J. F.; Ganopolski, A.; McManus, J.; Praetorius, S.; de Vernal, A.; Abe-Ouchi, A.; Cheng, H.; Claussen, M.; Crucifix, M.; Gallopín, G.; Iglesias, V.; Kaufman, D. S.; Kleinen, T.; Lambert, F.; van der Leeuw, S.; Liddy, H.; Loutre, M.-F.; McGee, D.; Rehfeld, K.; Rhodes, R.; Seddon, A. W. R.; Trauth, M. H.; Vanderveken, L.; Yu, Z. Past Abrupt Changes, Tipping Points and Cascading Impacts in the Earth System. Nature Geoscience 2021, 14 (8), 550-558. https://doi.org/10.1038/s41561-021-00790-5.

5. Lenton, T. M.; Rockström, J.; Gaffney, O.; Rahmstorf, S.; Richardson, K.; Steffen, W.; Schellnhuber, H. J. Climate Tipping Points-Too Risky to Bet Against. 2019.
6. Ridley, J. K.; Lowe, J. A.; Hewitt, H. T. How Reversible Is Sea Ice Loss? The Cryosphere 2012, 6 (1), 193-198. https://doi.org/10.5194/tc-6-193-2012.

7. Lenton, T. M. Arctic Climate Tipping Points. AMBIO 2012, 41 (1), 10-22. https://doi.org/10.1007/s13280-011-0221-x.

8. Robinson, A.; Calov, R.; Ganopolski, A. Multistability and Critical Thresholds of the Greenland Ice Sheet. Nature Climate Change 2012, 2 (6), 429-432. https://doi.org/10.1038/nclimate1449.

9. Garbe, J.; Albrecht, T.; Levermann, A.; Donges, J. F.; Winkelmann, R. The Hysteresis of the Antarctic Ice Sheet. Nature 2020, 585 (7826), 538-544. https://doi.org/10.1038/s41586-020-2727-5.

10. Lenton, T. M. Early Warning of Climate Tipping Points. Nature Climate Change 2011, 1 (4), 201-209. https://doi.org/10.1038/nclimate1143.

11. Ditlevsen, P. D.; Johnsen, S. J. Tipping Points: Early Warning and Wishful Thinking. Geophysical Research Letters 2010, 37 (19).

12. Boers, N. Observation-Based Early-Warning Signals for a Collapse of the Atlantic Meridional Overturning Circulation. Nature Climate Change 2021, 11 (8), 680-688.

13. Boers, N.; Rypdal, M. Critical Slowing down Suggests That the Western Greenland Ice Sheet Is Close to a Tipping Point. Proceedings of the National Academy of Sciences 2021, 118 (21).

14. Walton, J. L.; Levontin, P.; Barons, M. J.; Workman, M.; Mackie, E.; Kleineberg, J. Communicating Climate Risk: A Toolkit; AU4DM Network: London, UK, 2021.

15. Rahmstorf, S.; Box, J. E.; Feulner, G.; Mann, M. E.; Robinson, A.; Rutherford, S.; Schaffernicht, E. J. Exceptional Twentieth-Century Slowdown in Atlantic Ocean Overturning Circulation. Nature Climate Change 2015, 5 (5), 475-480. https://doi.org/10.1038/ nclimate2554.

16. Piecuch, C. G. Likely Weakening of the Florida Current during the Past Century Revealed by Sea-Level Observations. Nature Communications 2020, 11 (1), 3973. https://doi.org/10.1038/s41467-020-17761-w.

17. Zhu, C.; Liu, Z. Weakening Atlantic Overturning Circulation Causes South Atlantic Salinity Pile-Up. Nature Climate Change 2020, 10 (11), 998-1003. https://doi.org/10.1038/s41558-020-0897-7.

18. Caesar, L.; McCarthy, G. D.; Thornalley, D. J. R.; Cahill, N.; Rahmstorf, S. Current Atlantic Meridional Overturning Circulation Weakest in Last Millennium. Nature Geoscience 2021, 14 (3), 118-120. https://doi.org/10.1038/s41561-021-00699-z.

19. Rosier, S. H.; Reese, R.; Donges, J. F.; De Rydt, J.; Gudmundsson, G. H.; Winkelmann, R. The Tipping Points and Early Warning Indicators for Pine Island Glacier, West Antarctica. The Cryosphere 2021, 15 (3), 1501-1516.

20. DeConto, R. M.; Pollard, D. Contribution of Antarctica to Past and Future Sea-Level Rise. Nature 2016, 531 (7596), 591-597. https://doi.org/10.1038/nature17145.

21. Edwards, T. L.; Brandon, M. A.; Durand, G.; Edwards, N. R.; Golledge, N. R.; Holden, P. B.; Nias, I. J.; Payne, A. J.; Ritz, C.; Wernecke, A. Revisiting Antarctic Ice Loss Due to Marine Ice-Cliff Instability. Nature 2019, 566 (7742), 58-64. https://doi.org/10.1038/s41586-019-0901-4. 
22. Lai, C.-Y.; Kingslake, J.; Wearing, M. G.; Chen, P.-H. C.; Gentine, P.; Li, H.; Spergel, J. J.; van Wessem, J. M. Vulnerability of Antarctica's Ice Shelves to MeltwaterDriven Fracture. Nature 2020, 584 (7822), 574-578. https://doi.org/10.1038/s41586-020-2627-8.

23. Lhermitte, S.; Sun, S.; Shuman, C.; Wouters, B.; Pattyn, F.; Wuite, J.; Berthier, E.; Nagler, T. Damage Accelerates Ice Shelf Instability and Mass Loss in Amundsen Sea Embayment. Proc Natl Acad Sci USA 2020, 117 (40), 24735. https://doi.org/10.1073/pnas.1912890117.

24. Salati, E.; Dall'Olio, A.; Matsui, E.; Gat, J. R. Recycling of Water in the Amazon Basin: An Isotopic Study. Water Resources Research 1979, 15 (5), 1250-1258. https://doi.org/10.1029/WR015i005p01250.

25. Amigo, I. When Will the Amazon Hit a Tipping Point? Nature 2020, No. 578, 505-507. https://doi.org/10.1038/d41586-020-00508-4.

26. Matricardi Eraldo Aparecido Trondoli; Skole David Lewis; Costa Olívia Bueno; Pedlowski Marcos Antonio; Samek Jay Howard; Miguel Eder Pereira. Long-Term Forest Degradation Surpasses Deforestation in the Brazilian Amazon. Science 2020, 369 (6509), 1378-1382. https://doi.org/10.1126/science.abb3021.

27. Qin, Y.; Xiao, X.; Wigneron, J.-P.; Ciais, P.; Brandt, M.; Fan, L.; Li, X.; Crowell, S.; Wu, X.; Doughty, R.; Zhang, Y.; Liu, F.; Sitch, S.; Moore, B. Carbon Loss from Forest Degradation Exceeds That from Deforestation in the Brazilian Amazon. Nature Climate Change 2021, 11 (5), 442-448. https://doi.org/10.1038/s41558-021-01026-5.

28. Bullock, E. L.; Woodcock, C. E.; Souza Jr., C.; Olofsson, P. Satellite-Based Estimates Reveal Widespread Forest Degradation in the Amazon. Global Change Biology 2020, 26 (5), 2956-2969.

https://doi.org/10.1111/gcb.15029.
29. Longo, M.; Saatchi, S.; Keller, M.; Bowman, K.; Ferraz, A.; Moorcroft, P. R.; Morton, D. C.; Bonal, D.; Brando, P.; Burban, B.; Derroire, G.; dos-Santos, M. N.; Meyer, V.; Saleska, S.; Trumbore, S.; Vincent, G. Impacts of Degradation on Water, Energy, and Carbon Cycling of the Amazon Tropical Forests. Journal of Geophysical Research: Biogeosciences 2020, 125 (8), e2020JG005677. https://doi.org/10.1029/2020JG005677.

30. Gomez, N.; Weber, M. E.; Clark, P. U.; Mitrovica, J. X.; Han, H. K. Antarctic Ice Dynamics Amplified by Northern Hemisphere Sea-Level Forcing. Nature 2020, 587 (7835), 600-604. https://doi.org/10.1038/s41586-020-2916-2.

31. Ciemer, C.; Winkelmann, R.; Kurths, J.; Boers, N. Impact of an AMOC Weakening on the Stability of the Southern Amazon Rainforest. The European Physical Journal Special Topics 2021, 230 (14), 3065-3073. https://doi.org/10.1140/epjs/s11734-021-00186-x.

32. Steffen, W.; Rockström, J.; Richardson, K.; Lenton, T. M.; Folke, C.; Liverman, D.; Summerhayes, C. P.; Barnosky, A. D.; Cornell, S. E.; Crucifix, M.; Donges, J. F.; Fetzer, I.; Lade, S. J.; Scheffer, M.; Winkelmann, R.; Schellnhuber, H. J. Trajectories of the Earth System in the Anthropocene. PNAS 2018, 201810141. https://doi.org/10.1073/pnas.1810141115.

33. Wunderling, N.; Donges, J. F.; Kurths, J.; Winkelmann, R. Interacting Tipping Elements Increase Risk of Climate Domino Effects under Global Warming. Earth Syst. Dynam. 2021, 12 (2), 601-619. https://doi.org/10.5194/esd-12-601-2021.

\section{THE COP26 UNIVERSITIES NETWORK}

The Climate Risk Notes series is produced in association with the COP26 Universities Network, a growing group of more than 80 UK-based universities and research centres working together to help deliver an ambitious outcome at the UN Climate Summit in Glasgow and beyond. The Climate Risk Notes crystallise and expand on the learnings from the Climate Risk Summit (29th September - 1st October 2021), which aimed to bring key information on the risks of climate change, and their communication to decision-makers, to the attention of a wider audience ahead of COP26. This technical briefing represents the views of its author (listed on page one) and not necessarily that of every University or institution participating in the network. For more information about the COP26 Universities Network, please contact cop26universities@imperial.ac.uk.

\section{图图 UNIVERSITY OF

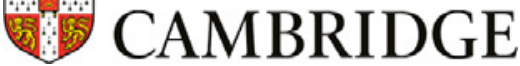

\section{CAMBRIDGE} $\mathrm{ZERO}_{2}$

\section{HOW TO CITE THIS PAPER}

Mackie, E. (2021). Tipping Points in the Earth System. COP26 Universities Network Climate Risk Note. 